\title{
Sea-blue histiocytes syndrome: Case report and review of literature
}

\author{
Mounira El Euch, Fatma Ben Fredj Ismail, Amel Rezgui, Monia Karmani, Belgacen Mrad, \\ Hassen Hosi Mhiri, Chedia Laouani Kechrid \\ Department of Internal Medicine, Sahloul Hospital, Soussa, Tunisia \\ Email: ach mounira@hotmail.com, bfi.fatma@yahoo.fr, rezguiamel@yahoo.fr, chedia.kechrid@rns.tn
}

Received 30 December 2011; revised 10 February 2012; accepted 2 March 2012

\begin{abstract}
A 57-year-old female was admitted with pancytopenia, and mild splenomegaly. The multiple myeloma diagnosis was wrongly made since the discovery of monoclonal peak to the protein electrophoresis. Further microscopic examination of bone marrow revealed the accumulation of sea-blue histiocytes. The evolution was stable and the patient did not receive any treatment due to the lack of nervous symptoms.
\end{abstract}

Keywords: Syndrome of the Sea-Blue Histiocyte; Pancytopenia; Splenomegaly

\section{BACKGROUND}

The syndrome of the sea-blue histiocyte is a rare disorder first described by Silverstein et alin 1970 [1]. It was given the name due to the histiocyte color upon May-Giemsa staining. The etiology is unknown. This disorder is classified as either primary or secondary; most cases are secondary to lipid metabolic diseases. The clinical course is usually benign but some cases develop fatal liver cirrhosis [2-4]. We report a case of this syndrome with a review of the literature.

\section{CASE REPORT}

A 57-year-old female was referred to Gastrology department for further examination of anemia. She was the product of consanguineous marriage. It was not similar cases in her family. She had not fever. The hemodynamic parameters were normal. The spleen was slightly palpable. We did not detect any peripheral lymphadenomegaly.

The diagnosis of portal hypertension was referred to the presence of esophageal varicosity grade II to upper gastrointestinal endoscopy with probable liver cirrhosis.

The patient we was addressed for exploration of a spike in serum protein electrophoresis.

The examination was a blood pressure at $14 / 9 \mathrm{~cm} \mathrm{Hg}$; a temperature at $37.3^{\circ}$, a BMI at $25 \mathrm{~kg} / \mathrm{m}^{2}$ and a pleno- megaly at $3 \mathrm{~cm}$ from the costal margin. Laboratory investigations showed the renal failure with urea at 23.4 $\mathrm{mmol} / \mathrm{l}$, creatinine at $186 \mu \mathrm{moles} / \mathrm{l}$, Natremia at $136 \mathrm{mg} / \mathrm{l}$, $\mathrm{K}^{+}$at $4.8 \mathrm{mg} / \mathrm{l}, \mathrm{Na}^{+}$urine $=42 \mathrm{mmol} / \mathrm{d}$; urinary $\mathrm{K}^{+}=$ $34.34 \mathrm{mmol} /$ day; $24 \mathrm{~h}$ proteinuria $=0.34 \mathrm{~g} ; \mathrm{Ca}^{++}=2.29$ $\mathrm{mg} / \mathrm{l}, \mathrm{CRP}<5, \mathrm{TP}=82 \%$.

The blood count showed pancytopenia with $\mathrm{GB}=$ 2910; $\mathrm{PNN}=2000 ;$ lymphocytes $=5800$, monocytes $=$ 3100 ; eosinophiles $=10$, basophiles $=100 ; \mathrm{Hb}=8.7 \mathrm{~g} / \mathrm{dl}$, $\mathrm{MCV}=83.6 \mathrm{fl} ; \mathrm{MCH}=25.1 \mathrm{pg}$, reticulocytes $=48,235 /$ $\mu 1$, platelets $=54,000 / \mu$.

Electrophoresis of serum protein showed: albumin $=$ 35.8; $\alpha 1$ globulin $=3.5, \alpha 2=7 ; \beta 1=4.5, \beta 2=2.7$ and a globulin spike to $20.1 \mathrm{~g} / 1$. The blood immunophenotyping was IgG kappa.

The search for urinary light chains was positive with a rate of $31.5 \mathrm{mg} /$ day. The dosage of $\beta 2$ microglobulin was $10,830 \mu \mathrm{g} / \mathrm{l}$. The skull radiograph (Figure 1) was without abnormalities. The diagnosis of multiple myeloma was discussed and sternal puncture did not show plasma cells but rather the presence of histiocytes.

Bone marrow biopsy showed a marrow made of wealth between 1 and 2, the seat of histiocytes with abundant cytoplasm vacuolated, the vacuoles are of unequal size, positive PAS staining and Giemsa negative for Perls stain, concluding the diagnosis histiocytosis of "blue sea". The evolution of our patient was stable by anemic syndrome corrected symptomatically at regular controls.

\section{DISCUSSION}

The sea-blue histiocyte syndrome, similar to NiemannPick disease, is a congenital, hereditary histiolipidosis due to an inborn enzymatic error. Accumulation of non saturated, oxidated, polymerized lipids is observed; ceroids of lipofuscin, glycophospholipids and sphingomyelin, like bulky granules 1 to $3 \mu$ in diameter, turn blue with May Grunewald staining, orange reddish with PAS and black with Sudan III and osmic acid.

The sea-blue histiocytes are preferably located at the bone marrow, liver and spleen and less frequently in 


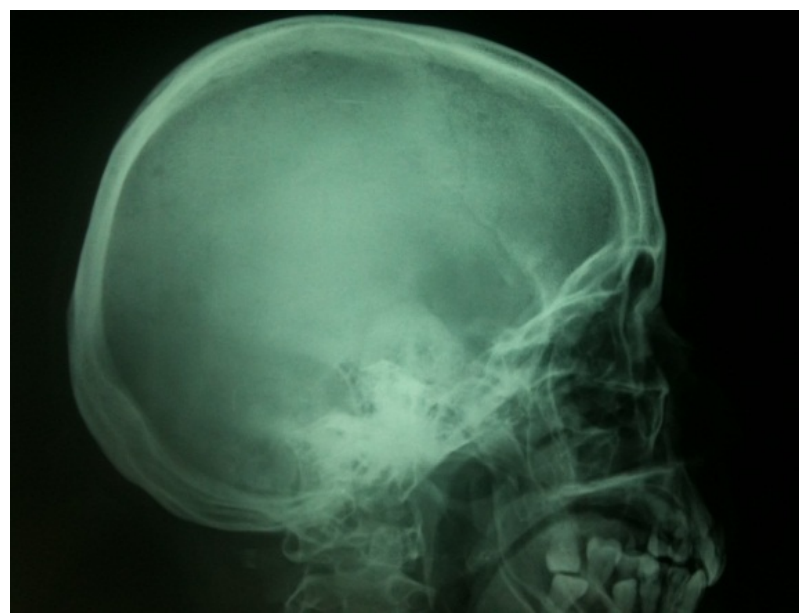

Figure 1. Skull radiograph without abnormalities.

lymph nodes, lungs and some other organs [1]. Our patient had only splenomegaly without these other localizations of the histiocytes.

In patients with myelofibrosis, extramedullary haematopoiesis commonly occurs in the spleen and liver, but rarely in the lymph nodes [2]. In these organs, fibrosis frequently develops in association with megakaryocyte infiltration [3]. On the other hand, macrophages loaded with cytoplasmic granules staining blue with Giemsa, socalled sea-blue histiocytes, are commonly seen in various organs including the lungs in Niemann-Pick disease, and occasionally in the bone marrow and spleen as a seconddary phenomenon associated with a variety of acquired hematological disorders, such as chronic myelogenous leukemia, chronic immune thrombocytopenic purpura, myelodysplastic syndrome, and polycythaemia rubravera [4-6]. Fortunately, our patient hadn't these hematological disorders. Pulmonary involvement is a complication occurring frequently in the inherited disorder [7,8], but rarely in acquired disorders.

Within the spleen, which in myelofibrosis functions as an extramedullary hematopoietic organ, monocytes differentiate from hematopoietic stem cells, proliferate, and are transformed into sea-blue histiocytes. Because seablue histiocytes have a large cytoplasm, as do megakaryocytes, it is considered likely that the lungs, and probably the liver, function as a physiological sieve of circulating monocytes, which changed into sea-blue histiocytes in the bone marrow and the spleen, respectively. Moreover, it has been reported that, in a labeling experiment with $3 \mathrm{H}$-thymidine, about $15 \%$ and $56 \%$ of mice monocytes leaving the circulation become pulmonary macrophages and Kupffer cells, respectively [9-11].

Consequently, a heavy accumulation of sea-blue histiocytes in the spleen of this patient could be explained by these hypotheses. The lysosomal enzyme pathway in macrophages of these disorders results in saturation for re- moval of the membrane lipid, and the cells are transformed into sea-blue histiocytes $[9,10]$. The sea-blue histiocytes are usually observed in the bone marrow and spleen, where the majority of the blood cells are destoryed and phagocytosed. On the other hand, Links et al. [12] reported a case of pulmonary tuberculosis in which pulmonary interstitial infiltration of pseudo-Gaucher cells was caused by incomplete breakdown of mycobacterial cell wall.

Sea-blue histiocytosis [13] describes splenomegaly in the presence of numerous histiocytes stained a seablue color. This finding occurs in several conditions, including cholesterol ester storage disease and other lysosomal disorders, Niemann-Pick variant, Gaucher disease, severe hypertriglyceridemia, lecithin-cholesterol acyltransferase deficiency, and Tangier disease [2]. The primary syndrome of sea-blue histiocytosis has no known etiology, although a biochemical derangement in lipid metabolism has been hypothesized [14]. One of the major apolipoproteins controlling lipoprotein metabolisms is apolipoprotein E (apoE) [15]. Splenomegaly has not been associated with this lipid disorder, except in cases of severe hypertriglyceridemia [16]. We described a primary sea blue histiocytosis which had normal serum triglyceride concentrations, but a spike in protein electrophoresis like in myeloma.

Nguyen et al. call attention to a new etiology for seablue histiocytosis and point out that the 149 variant of apoE appears to stimulate cholesterol ester accumulation in macrophages and could be associated with targeting of lipoproteins to macrophages. Splenectomy unmasked the lipoprotein defect and allowed expression of the hyperlipidemia and accumulation of remnant lipoproteins [17]. The cytochemical reaction on bone marrow smears in this patient and previous cases $[18,19]$ suggested that the storage material in the cytoplasmic granules was glycolipid and/or phospholipid. The etiology of this lipid storage disease is unknown, but most of the reported cases were predominantly females as is the subject of the present report. Some authors have suggested that it is a hereditary disorder $[19,20]$ but the disorder may be acquired and associated with other diseases [21,22].

The prognosis is variable: fatal in the central nervous system location, relatively mild in cases of spleen and bone marrow location. The possibility of complicating hepatic cirrhosis and/or pulmonary fibrosis is always present [1]. Our patient didn't develop any complication but regular controls are necessary in order to treat at time these further manifestations.

\section{CONCLUSION}

This case described a primary sea blue histiocytosis which had normal serum triglyceride concentrations. We did 
not find a particular entity to our patient and her syndrome stay primary. The histology stays of great diagnostic input in this rare entity which stays without a specific treatment.

\section{REFERENCES}

[1] Etcheverry, R., Daiber, A., Boris, E. and Durán, N. (1991) Sea-blue histiocyte syndrome. Revue of Medecine Cheldren, 119, 1008-1015.

[2] Glew, R.H., Haese, W.H. and McIntyre, P.A. (1973) Myeloid metaplasia with myelofibrosis. The clinical spectrum of extramedullary hematopoiesis and tumor formation. Johns Hopkins Medical Journal, 132, 253-270.

[3] Pereira, A., Bruguera, M., Cervantes, F. and Rozman, C. (1988) Liver involvement at diagnosis of primary myelofibrosis: A clinicopathological study of twenty-two cases. European Journal of Haematology, 40, 355-361. doi:10.1111/j.1600-0609.1988.tb00191.x

[4] Howard, M.R. and Kesteven, P.J.L. (1993) Sea blue histiocytosis: A common abnormality of the bone marrow in myelodysplastic syndromes. Journal of Clinical Pathology, 46, 1030-1032. doi:10.1136/jcp.46.11.1030

[5] Takahashi, K., Terashima, K., Kojima, M., Yoshida, H. and Kimura, H. (1977) Pathological, histochemical and ultrastructural studies on sea-blue histiocytes and Gaucher-like cells in acquired lipidosis occurring in leukemia. Acta Pathology of Japan, 27, 775-797.

[6] Rywlin, A.M., Hernandez, J.A., Chastain, D.E. and Pardo, V. (1971) Ceroidhistiocytosis of spleen and bone marrow in idiopathic thrombocytopenic purpura (ITP): A contribution to the understanding of the sea-blue histiocyte. Blood, 37, 587-593.

[7] Lachman, R., Crocker, A., Schulman, J. and Strand, R. (1973) Radiological findings in Niemann-Pick disease. $R a-$ diology, 108, 659-664.

[8] Quattrin, N., De Rosa, L., Quattrin Jr., S. and Cecio, A. (1978) Sea blue histiocytosis: A clinical cytologic and nosographic study on 23 cases. KlinWschr, 56, 17-30. doi:10.1007/BF01476739

[9] Howard, M.R. and Kesteven, P.J.L. (1993) Sea blue histiocytosis: A common abnormality of the bone marrow in myelodysplastic syndromes. Journal of Clinical Pathology, 46, 1030-1032. doi:10.1136/jcp.46.11.1030

[10] Rywlin, A.M., Hernandez, J.A., Chastain, D.E. and Pardo, V. (1971) Ceroidhistiocytosis of spleen and bone marrow in idiopathic thrombocytopenic purpura (ITP): A contribution to the understanding of the sea-blue histiocyte.
Blood, 37, 587-593.

[11] Van OudAlblas, B. and van Furth, R. (1979) Origin, kinetics, and characteristics of pulmonary macrophages in the normal steady state. Journal of Experimental Medicine, 149, 1504-1518. doi:10.1084/jem.149.6.1504

[12] Links, T.P., Karrenbeld, A., Steensma, J.T., et al. (1992) Fatal respiratory failure caused by pulmonary infiltration by pseudo-Gaucher cells. Chest, 101, 265-266. doi:10.1378/chest.101.1.265

[13] Silverstein, M.N., Ellefson, R.D. and Ahern, E.J. (1970) The syndrome of the sea-blue histiocyte. New England Journal of Medicine, 282, 1-4. doi:10.1056/NEJM197001012820101

[14] Silverstein, M.N. and Ellefson, R.D. (1972) The syndrome of the sea-blue histiocyte. SeminHematology, 9, 299-307.

[15] Mahley, R.W. (1988) Cholesterol transport protein with expanding role in cell biology. Science, 240, 622-630. doi:10.1126/science.3283935

[16] Roberts, W.C., Levy, R.I. and Fredrickson, D.S. (1970) Hyperlipoproteinemia. A review of the five types with first report of necropsy findings in type 3. Archives of Pathology, 90, 46-56.

[17] Nguyen, T.T., Kruckeberg, K.E., O’Brien, J.F., Ji, Z.S., Karnes, P.S., Crotty, T.B., Hay, I.D., Mahley, R.W. and O'Brien, T. (2000) Familial splenomegaly: Macrophage hypercatabolism of lipoproteins associated with apolipoprotein E mutation [apolipoprotein E (delta149 Leu)]. Journal of Clinicol Endocrinology and Metabolism, 85, 4354-4358. doi:10.1210/jc.85.11.4354

[18] Jones, B., Gilbert, E.F., Zugibe, F.T. and Thompson, H. (1970) Sea-blue histiocyte disease in siblings. Lancet, 2, 73-75. doi:10.1016/S0140-6736(70)92642-5

[19] Silverstein, M.N., Ellefson, R.D. and Ahern, E.J. (1970) The syndrome of the sea-blue histiocyte. New England Journal of Medicine, 282, 1-4.

[20] Ardeman, S. and Lewis, J. G. (1972) Svndrome of the sea-blue histiocyte. Lancet, 1, 797. doi:10.1016/S0140-6736(72)90553-3

[21] Marshall, A.H.E. and Adams, C.W.M. (1958) An unusual form of lipidosis associated with thrombocytopenia and angiomata of the spleen. Journal of Pathology, 76, 159164. doi:10.1002/path. 1700760118

[22] Kattlove, H.E., Gaynor, E., Spivack, M. and Gottfried, E.L. (1970) Sea-blue indigestion. New England Journal of Medicine, 282, 630-631. doi:10.1056/NEJM197003122821120 